\title{
Is the anesthesiologist actually prepared for loss of airway or respiratory function? A cross-sectional study conducted in a tertiary hospital
}

\author{
Helga Vasconcelos ${ }^{1}$, Camila Cavalcante Bomfim², Maria Julia Gonçalves de Mello ${ }^{3}$, Paulo Sérgio Gomes Nogueira Borges ${ }^{4}$, \\ Tania Cursino de Menezes Couceiro ${ }^{5}$, Flávia Augusta de Orange ${ }^{6}$

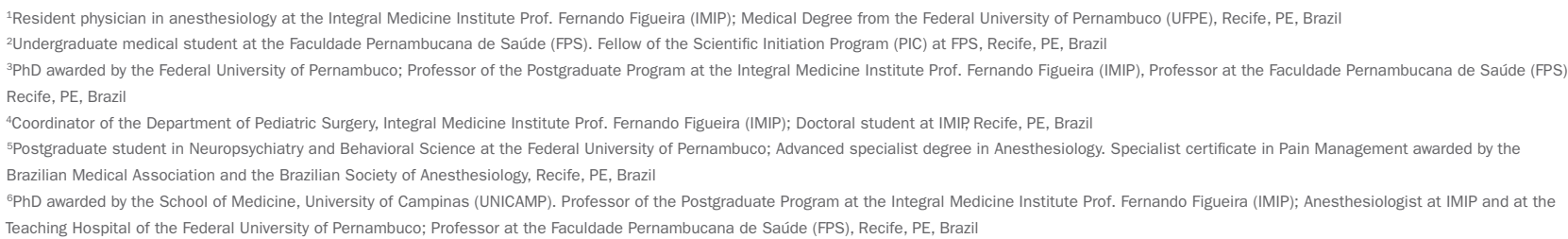

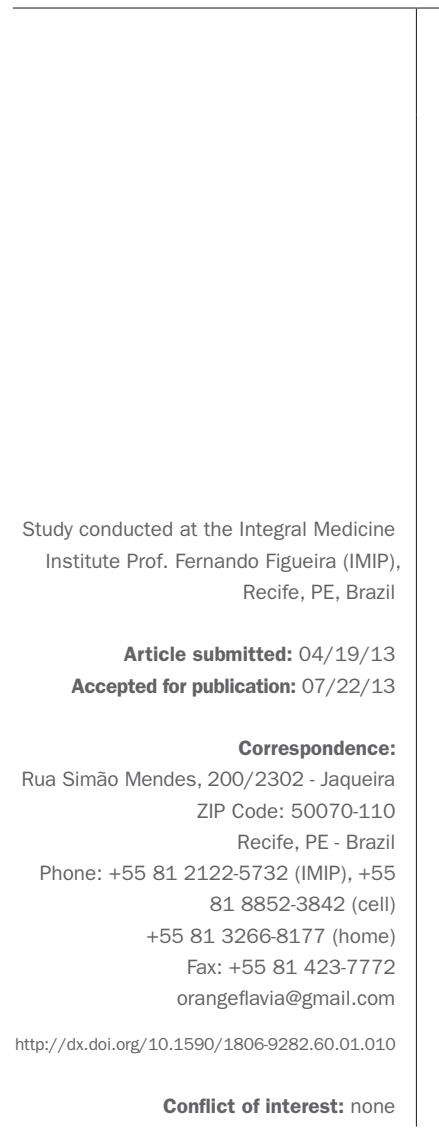

\section{SUMMARY}

Objective: To identify compliance with the procedures for securing the airway of patients submitted to anesthesia, defined as highly recommended in the World Health Organization Surgical Safety Checklist.

Methods: A prospective, cross-sectional, observational study was conducted with 87 patients aged 18 to 60 years, classified as ASA grade 1 or 2 according to the American Society of Anesthesiologists' Physical Status Classification. The study variables consisted of: whether the Mallampati test had been performed, whether equipment was readily available for orotracheal intubation, whether the correct placement of the endotracheal tube was verified, whether patient ventilation was monitored and whether fasting was confirmed. Prevalence ratios and their respective $95 \%$ confidence intervals were calculated as measures of relative risk. Statistical significance was defined at $5 \%$.

Results: It was found that in $87.4 \%$ of patients, the airway was not evaluated using the Mallampati classification and in $51.7 \%$ of cases, preoperative fasting was not confirmed. In $29.9 \%$ of cases, the ready availability of equipment for orotracheal intubation was not verified. In all of the cases in which the availability of this equipment was not checked, the patient was submitted to regional anesthesia, with a statistically significant difference compared to the cases in which the patient was submitted to general anesthesia.

Conclusion: Measures considered essential for the safety of the patient during surgery are still being ignored.

Key words: Anesthesia, conduction anesthesia, patient safety, airway management.

\section{INTRODUCTION}

No progress has had such a significant impact on the care of surgical patients as the advances made in the safe practice of anesthesiology $y^{1,2}$. The Ministry of Health, in partnership with the Pan American Health Organization, put together a safe surgery checklist following the stages recommended by the World Health Organization (WHO) ${ }^{3,4}$. Of the steps that fall under the responsibility of the anesthesiologist, objective 3: "The team will recognize and ef- fectively prepare for life-threatening loss of airway or respiratory function" is specifically noteworthy ${ }^{5-7}$.

During anesthesia, a reduction in the tonus of the upper airways, with the consequent collapse of these structures, together with decreased protective reflexes, exposes the patient to the risk of aspiration. In addition, the majority of anesthetics reduce the respiratory drive and the administration of muscle relaxants at clinical doses 
causes complete paralysis, preventing patients from breathing on their own. In this situation, the anesthetized patient is extremely vulnerable to hypoxia and completely dependent on the anesthesiologist to maintain the airway and ventilation. ${ }^{7}$

The Guidelines for Safe Surgery list the following procedures as being highly recommended to secure the patient's airway: all patients should undergo an objective evaluation of their airway before induction of anesthesia, even when orotracheal intubation is not anticipated; the anesthesiologist should have a planned strategy for managing the airways and be prepared to execute it, and alternatives should be available for potential difficulties; after intubation, the anesthesiologist should always confirm endotracheal placement by listening for breath sounds as well as gastric ventilation; the anesthesiologist should confirm adequate ventilation after intubation by use of pulse oximetry and capnography; patients undergoing elective surgery should be fasting prior to anesthesia. ${ }^{3}$

The principal objective of the present study was to identify whether the highly recommended procedures for managing the airways of patients submitted to anesthesia, based on the WHO anesthesia safety guidelines, are being followed.

\section{Methods}

A prospective, observational, cross-sectional study was conducted with 87 patients submitted to anesthesia in the adult surgical ward of the Integral Medicine Institute Prof. Fernando Figueira (IMIP), in Recife, state of Pernambuco in northeastern Brazil, between May 2011 and April 2012. Patients included in the study agreed to participate and signed an informed consent form. The study was previously approved by the institution's internal review board under reference \# 2299.

Patients aged 18 to 60 years and classified according to the American Society of Anesthesiologists (ASA) physical status classification as ASA I or II were eligible for the study, while outpatients were excluded.

In addition to the demographic variables (sex and age), data were also collected with respect to the extent of the surgery performed, whether the patient had been evaluated according to the Mallampati classification, whether equipment was readily available for orotracheal intubation, whether the correct placement of the endotracheal tube was verified, whether patient ventilation was monitored and whether fasting was confirmed. Furthermore, data were collected on the occurrence of intraoperative complications such as hypoxia, esophageal intubation and any difficulty with orotracheal intubation.
Sample size was calculated using the Statcalc module of the Epi-Info program (Centers for Disease Control and Prevention, Atlanta, GA, USA), version 3.5.3, based on data in the literature ${ }^{5,8}$ reporting an incidence of anesthetic complications of 3-16\%. Considering a power of $80 \%$ and an alpha error of $5 \%$, sample size was calculated at 85 patients.

The type of anesthesia was classified as general or regional and the extent of surgery as: major, in the case of surgeries in which the probability of fluid and blood loss is high (emergency surgeries, wound in the precordial region, vascular surgeries such as abdominal aortic aneurysm repair); moderate, when the probability of fluid or blood loss is moderate (carotid endarterectomy, head and neck surgery, hip prosthesis and transurethral resection of the prostate); and, finally, minor surgeries, when the probability of fluid and blood loss is slight (otorhinolaryngologic surgery, plastic surgery, endoscopy, ophthalmologic surgery and fracture repair). ${ }^{9}$

The Mallampati test ${ }^{10}$ is a classification system used to correlate the oropharyngeal space with the degree of difficulty in performing direct laryngoscopy and tracheal intubation. Patients are classified as: class 1 , when the soft palate, fauces, uvula, anterior and posterior pillars are visible; class 2 , when the soft palate, fauces and uvula are visible; class 3 , when the soft palate and base of the uvula are visible; and class 4 , when the soft palate is not visible at all. Whether or not the Mallampati classification was applied was considered a dichotomous variable.

The ready availability of the material required for orotracheal intubation was considered to have been verified if the anesthesiologist confirmed that all the material required for a possible intubation was present and had been tested, including the laryngoscope blade, endotracheal tubes, tracheal tube introducer, tracheal tube, mask and ventilation system. In the absence of one of these components, it was interpreted that the material required for intubation was unavailable.

Correct placement of the endotracheal tube is confirmed by auscultation of bilateral vesicular breath sounds over the chest, and the absence of epigastric sounds. If auscultation was not performed, it was considered that the correct placement of the orotracheal tube had not been confirmed. The position of the tube should be monitored and capnography and pulse oximetry should be used to check whether ventilation/ oxygenation is adequate. Capnography determines expiratory $\mathrm{CO}_{2}$ concentration and serves as a valuable monitor of ventilation and pulmonary perfusion. ${ }^{11} \mathrm{On}$ the other hand, pulse oximetry measures oxygen satu- 
ration in arterial blood in a non-invasive manner, and also indicates tissue perfusion and measures heart rate. ${ }^{11}$ Whether or not capnography and pulse oximetry were used during anesthesia was also taken into account.

Intraoperative complications consisted of difficulties with intubation, hypoxia and esophageal intubation. Hypoxia was defined as reduced tissue oxygen levels, identified by a pulse oximeter indicating peripheral oxygen saturation $<90 \%{ }^{12}$ Esophageal intubation was defined as failed tracheal intubation, identified by the absence of vesicular breath sounds and the presence of gastric sounds during ventilation, or, more precisely, by an absent capnographic waveform. Difficult intubation was defined as when an experienced anesthesiologist, with the required material and using the correct techniques, encountered difficulty in performing direct laryngoscopy or tracheal intubation. ${ }^{11}$

Preoperative fasting was evaluated by questioning the patient with respect to his/her food intake prior to the procedure. The recommended fasting period for adults is two hours for clear liquids, 6 hours for light food and 8 hours for fatty or fried foods. ${ }^{13}$

The patients were recruited at the surgical ward of the Integral Medicine Institute Prof. Fernando Figueira (IMIP) and all of those who met the admission criteria were invited to participate in the study. The patients were interviewed by the principal investigator using a standard form with pre-coded answers. As the study concerns the observation of anesthetic practices, the anesthesiologists involved in performing the procedures on the patients participating in the study were asked to sign an informed consent form; however, they were not given any information on what practices were to be observed in order to avoid any change in conduct. In addition, at the end of the study and after the results had been made available, the anesthesiologists were asked to sign a form authorizing publication of the findings.

After double data entry and the correction of any inconsistencies, data analysis was performed using the Epi-Info program (Centers for Disease Control and Prevention, Atlanta, GA, USA), version 3.5.3. Frequency tables were constructed for all the variables. In addition, $2 \times 2$ contingency tables were constructed for the variables: whether or not the Mallampati test was performed, whether or not preoperative fasting was confirmed and whether or not the necessary material was available for orotracheal intubation, according to whether general or regional anesthesia was used. The chi-square test was used to verify the association between the variables stu- died, and Yates' correction or Fisher's exact test was used when one of the values was $<5$. A significance level of $5 \%$ was adopted.

\section{Results}

A total of 88 patients were selected for the study; however, one patient was excluded because he presented signs of respiratory depression immediately before anesthesia induction; therefore, 87 patients were admitted to the study. The mean age of the patients in the study sample was $40 \pm 11$ years and the majority (66.7\%) were classified as ASA I. Approximately 63.2\% of the surgical procedures were minor surgeries and $71.3 \%$ of the anesthetic procedures consisted of regional blocks (Table 1). With respect to the type of surgery, $34.9 \%$ consisted of general surgical procedures, while $32.6 \%$ were cases of vascular surgery, $19.1 \%$ were orthopedic procedures and $2.3 \%$ were urological procedures.

\section{TABLE 1 Characteristics of the study sample}

\begin{tabular}{l|l|l}
\multirow{2}{*}{ Variables } & $\mathrm{n}=87$ & \multicolumn{2}{|}{} \\
\cline { 2 - 3 } Mean age (SD) & \multicolumn{2}{|l}{} \\
\hline ASA (n/\%) & $40.2(11.1)$ \\
\hline I & 58 & 66.7 \\
\hline II & 29 & 33.3 \\
\hline Extent of surgery (n/\%) & & \\
\hline Minor & 55 & 63.2 \\
\hline Major & 5 & 5.7 \\
\hline Moderate & 27 & 36.8 \\
\hline Anesthesia & & \\
\hline General & 25 & 28.7 \\
\hline Regional & 62 & 71.3 \\
\hline
\end{tabular}

$\mathrm{ASA}=$ American Society of Anesthesiologists e $\mathrm{SD}=$ standard deviation

As shown in Table 2, in the majority of the patients (87.4\%) the Mallampati test was not performed and in approximately half the cases $(51.7 \%)$ the anesthesiologist failed to confirm preoperative fasting. It was also found that in $29.9 \%$ of the procedures, the availability of material for orotracheal intubation was not verified.

Among the patients submitted to general anesthesia, orotracheal intubation was not confirmed by auscultation in the majority (68\%) of cases, being confirmed by capnography in $95.8 \%$ of cases. In one of the patients submitted to general anesthesia, airway permeability was maintained with the use of a laryngeal mask; therefore only the effectiveness of this technique was confirmed by capnography (Table 2). 
TABLE 2 Percentage of cases in which the recommended safe surgery procedures were performed

\begin{tabular}{|c|c|c|}
\hline \multirow[t]{2}{*}{ Variables } & \multicolumn{2}{|c|}{$\mathrm{n}=87$} \\
\hline & $n$ & $\%$ \\
\hline \multicolumn{3}{|l|}{ Mallampati test } \\
\hline Yes & 11 & 12.6 \\
\hline No & 76 & 87.4 \\
\hline \multicolumn{3}{|c|}{ Confirmation of preoperative fasting } \\
\hline Yes & 42 & 48.3 \\
\hline No & 45 & 51.7 \\
\hline \multicolumn{3}{|c|}{$\begin{array}{l}\text { Confirmation of orotracheal intubation by } \\
\text { auscultation* }\end{array}$} \\
\hline Yes & 7 & 28 \\
\hline No & 17 & 68 \\
\hline Not applicable ** & 1 & 4 \\
\hline \multicolumn{3}{|c|}{ Confirmation of intubation by capnography * } \\
\hline Yes & 23 & 95.8 \\
\hline No & 2 & 4.2 \\
\hline \multicolumn{3}{|c|}{$\begin{array}{l}\text { Verification of the availability of material for } \\
\text { orotracheal intubation }\end{array}$} \\
\hline Yes & 61 & 70.1 \\
\hline No & 26 & 29.9 \\
\hline
\end{tabular}

* Only for the patients submitted to general anesthesia.

** Use of laryngeal mask

The patients submitted to regional anesthesia were found to be less likely to have had their airway classified by the Mallampati test; however, this finding was not statistically significant. Likewise, fasting was less likely to have been checked in the case of patients submitted to regional anesthesia; nevertheless, this difference was not statistically significant. It was also found that when general anesthesia was scheduled, the availability of material for orotracheal intubation was checked, while in all cases in which verification was not made, the patient was to be submitted to regional anesthesia. This difference was statistically significant (Table 3 ).

Finally, only two patients (2.3\%) suffered a complication during anesthesia. In one case, orotracheal intubation proved difficult, with esophageal intubation occurring at the first attempt, resulting in mild hypoxia that was identified with no delay. A second attempt was then made at orotracheal intubation, this time successfully. A similar situation occurred with the second patient, although no sign of hypoxia was detected in this case.

\begin{tabular}{|c|c|c|c|c|}
\hline \multirow[t]{2}{*}{ Variables } & \multicolumn{2}{|l|}{$n=87$} & \multirow[b]{2}{*}{$\begin{array}{l}\text { PR } \\
(95 \% \mathrm{Cl})\end{array}$} & \multirow[b]{2}{*}{ P-value } \\
\hline & General & Regional & & \\
\hline \multicolumn{5}{|l|}{$\begin{array}{l}\text { Mallampati } \\
\text { test (n/\%) }\end{array}$} \\
\hline Yes & $6(54.5)$ & $5(45.5)$ & $0.4(0.23-0.89)$ & $0.09^{*}$ \\
\hline No & $19(25.0)$ & $57(75.0)$ & & \\
\hline \multicolumn{5}{|l|}{$\begin{array}{l}\text { Confirmation } \\
\text { of preoperative } \\
\text { fasting }(n / \%)\end{array}$} \\
\hline Yes & $10(23.8)$ & $32(76.2)$ & $1.4(0.70-2.7)$ & $0.45^{*}$ \\
\hline No & $15(33.3)$ & $30(66.7)$ & & \\
\hline \multicolumn{5}{|l|}{$\begin{array}{l}\text { Verification of } \\
\text { the availability } \\
\text { of material for } \\
\text { endotracheal } \\
\text { intubation } \\
(n / \%)\end{array}$} \\
\hline Yes & $25(41)$ & $36(59)$ & NC & $0.00 * *$ \\
\hline No & 0 & $26(100)$ & & \\
\hline
\end{tabular}

\section{Discussion}

The present study showed that in the majority of the patients (87.4\%) the Mallampati classification was not used to evaluate the airway and in approximately half the cases (51.7\%) the anesthesiologist failed to check whether the patient had complied with the requirement for preoperative fasting. Furthermore, in $29.9 \%$ of the anesthetic procedures, the anesthesiologists failed to check whether the material required for orotracheal intubation was available. Failure to perform the Mallampati test, confirm fasting or check the availability of the material for intubation occurred predominantly when regional anesthesia was scheduled; however, in comparison to cases of general anesthesia, a statistically significant difference was only found with respect to verification of the availability of the material required for orotracheal intubation. In addition, it should be noted that of the patients submitted to general anesthesia, orotracheal intubation was not confirmed by auscultation in the majority (68\%) of cases, being confirmed by capnography in $95.8 \%$ of cases. Only 
two patients (2.3\%) suffered some form of complication during anesthesia.

Motivated by the evidence of the substantial health damage inflicted by adverse events, most of which are preventable, the World Health Organization (WHO) has been encouraging the adoption of measures to improve health safety based on monitoring systems. ${ }^{1,14,15}$ The first challenge to be tackled was that of healthcare-associated infection, while the second deals with safety during surgery. In Brazil, the Ministry of Health, together with the Pan American Health Organization and the regional office for the Americas of the World Health Organization, launched a manual containing ten basic, essential objectives for any surgery, the third of which is particularly noteworthy: "The team will recognize and effectively prepare for life-threatening loss of airway or respiratory function". ${ }^{3}$

In this manual, some measures are considered highly recommended in order to secure the airway. The first measure emphasizes the need for all patients to undergo an objective evaluation of their airway prior to anesthesia induction, even when intubation is not anticipated, so that potential difficulties in airway management can be identified. Notwithstanding, the present study found that this evaluation is not routinely performed, principally when intubation is less likely, as in the case of regional blocks.

In 1985, Mallampati et al. conducted a study to evaluate signs predictive of difficult tracheal intubation. ${ }^{16}$ In 1987, Samson and Young proposed four different Mallampati classes, which have been used up to the present date as one of the principal tests for airway evaluation. According to this test, it is possible to predict whether orotracheal intubation will be difficult in any given patient. This allows the anesthesiologist to prepare airway support equipment, thus avoiding a situation in which unexpected difficulties with orotracheal intubation result in an unfavorable outcome, threatening the patient's life. ${ }^{17}$ Furthermore, most of the evidence suggests that the Mallampati test should be performed in all patients to be submitted to surgery and/or anesthesia, even those in whom orotracheal intubation is not expected, such as patients scheduled for a regional block, since the need for orotracheal intubation is always a possibility. ${ }^{17}$

In addition, another action considered indispensable is the need for the anesthesiologist to plan a strategy for securing the airway even when loss of airway is not expected. This consists of ensuring that all the equipment for orotracheal intubation is accessible and has been tested, as well as establishing a back-up plan for a difficult airway if necessary. ${ }^{5,18}$ These actions were not observed in this study. On the contrary, in $29.9 \%$ of cases, the availa- bility of this equipment was not checked. More precisely, in all the cases in which this action was ignored the patient was to be submitted to regional anesthesia.

Regarding confirmation of preoperative fasting by the anesthesiologist, the safe surgery checklist recommends that this procedure should always be carried out in the case of elective surgeries; therefore, compliance should be strict. Nevertheless, we found that in approximately half the cases, the anesthesiologist failed to confirm fasting, possibly because he/she assumed that the patients would comply with the preoperative instructions provided by the surgeon.

Also regarding the actions recommended in the Ministry of Health's manual, a step often forgotten by the anesthesiologist and one that merits particular attention refers to the recommendation that, following intubation, it is always necessary to confirm the correct placement of the tube by listening to the breath sounds through a stethoscope and to confirm adequate ventilation by capnography. However, what was found in the present study was that in around $68 \%$ of the patients, intubation was not confirmed by auscultation, in the majority of cases (98.5\%) being confirmed by capnography. Nevertheless, it is important to clarify that although the latter method is the most reliable means of evaluating orotracheal intubation, only auscultation is able to guarantee that selective intubation has not occurred and to monitor lung complications such as pneumothorax..$^{19}$

It is important to emphasize that, although the evidence suggests that not performing actions considered essential may result in an increase in the occurrence of unfavorable events, this was not found in the present study. On the contrary, the rate of complications was $2.3 \%$, a value well below figures published in the literature where rates range from $3 \%$ to $16 \%{ }^{4,8}$ This may be explained by the fact that in this study the surgeries were mostly minor and performed under regional anesthesia, whereas these details are not provided with any precision in the literature. It is possible that the rate of complications may be higher when major surgery is associated with a failure to comply with procedures aimed at improving the safety of anesthesia.

Nevertheless, although the rates of anesthetic/surgical complications are difficult to measure because of variations among cases, routinely performing the steps recommended in the checklist is believed to reduce the incidence of morbidity and mortality during surgery. Following a checklist throughout the entire anesthetic procedure is believed to represent an important step in implementing essential actions as routine, thus minimizing the human failures that often occur as the result of an excessive workload. ${ }^{20,21}$ 
Most of the communities worldwide that are concerned with patient safety believe that something has to be done to improve the safety and quality of risk management within the realm of healthcare. The existing processes are fragmented and information on what is wrong is sparse. An information system and the management of incidents based on a universal safety classification would probably contribute towards ensuring that measures were taken. ${ }^{22}$

Finally, in 2005, the World Health Organization's World Alliance for Patient Safety initiated a project to develop an International Classification for Patient Safety (ICPS) and to elaborate a classification system that would transform the data on patient safety collected from different systems into a common format to facilitate pooling, analysis and, principally, to provide knowledge on important and unified actions. ${ }^{14,23}$

It should also be emphasized that cross-sectional studies need to be analyzed with caution. In this type of study design, exposure and effect are measured at the same point in time, which makes it difficult to identify the time of exposure, i.e. whether this precedes the appearance of the disease or whether the presence of the disease alters the degree of exposure to a certain factor. Another disadvantage of this type of study design is the inability to exclude systematic bias observation, which consists of different evaluation for subgroups of patients. Likewise, those who are being observed can modify their behavior. However, in this study specifically, we believe that this bias was minimized through two conducts: the observer was not part of the surgical team and the members of this team were not initially informed of the real objectives of the research.

\section{Conclusion}

Actions considered essential for patient safety during surgery are still ignored; therefore, measures aimed at acquiring information and standardizing conduct may contribute towards improving surgical outcome.

\section{Authors' contributions}

$\mathrm{HV}$ participated in the data collection and in writing this manuscript. CCB participated in the data collection, in reviewing the literature and in writing this manuscript. $\mathrm{JM}$ conceived the idea for the protocol and reviewed this final version of the manuscript. PSGNB and TCMC collaborated in writing the manuscript. FAO, together with $\mathrm{JM}$, conceived the original idea for the protocol, supervised the study, wrote the manuscript and reviewed this final version.

\section{Ethics}

Details of the ethics committee approval: approval of this study (entry number: 2299) was provided by the Ethics Committee on Human Research of the Integral Medicine Institute Professor Fernando Figueira (IMIP).

\section{Resumo}

O anestesiologista está efetivamente preparado para perda da via aérea ou da função respiratória? Um estudo de corte transversal em hospital terciário

Objetivo: Identificar a realização de procedimentos altamente recomendados para assegurar a via aérea de pacientes submetidos a anestesia, previstos no manual de segurança anestésica da Organização Mundial da Saúde. Métodos: Realizou-se um estudo prospectivo do tipo transversal observacional, envolvendo 87 pacientes com idade entre 18 e 60 anos, ASA 1 e 2 de acordo com a classificação do Estado Físico pela Sociedade Americana de Anestesiologia. Variáveis estudadas: realização do teste de Mallampati, disponibilidade de material para intubação orotraqueal, confirmação do posicionamento do tubo endotraqueal, monitoração da ventilação do paciente e confirmação do jejum. Calculou-se a Razão de Prevalência (RP) e o seu Intervalo de Confiança a 95\% (IC 95\%) como medida do risco relativo. Adotou-se o nível de significância de $5 \%$.

Resultados: Em 87,4\% dos pacientes a via aérea não foi avaliada pelo teste de Mallampati e 51,7\% não tiveram seus jejuns pré-operatórios confirmados, e em $29,1 \%$ das anestesias não se verificou a disponibilidade de material para intubação orotraqueal. Todos os casos em que não ocorreu esta verificação o paciente foi submetido à anestesia regional, com diferença significativa entre os grupos $(p=0.00) .95,8 \%$ dos pacientes tiveram a intubação orotraqueal confirmada pela capnografia e $68 \%$ tiveram esta confirmação realizada pela ausculta.

Conclusão: Medidas consideradas essenciais para a segurança do paciente durante a cirurgia ainda são negligenciadas.

Unitermos: Anestesia, segurança, manuseio de vias aéreas.

\section{References}

1. World Health Organization. Guidelines for WHO guidelines. Geneva: Global Programme on Evidence for Health Policy; 2003.

2. Mellin-Olsen J, Staender S, Whitaker DK, Smith AF. The Helsinki Declaration on Patient Safety in Anaesthesiology. Eur J Anaesthesiol. 2010;27(7):592-7.

3. Organização Mundial da Saúde. Segundo desafio global para a segurança do paciente: Cirurgias seguras salvam vidas. Rio de Janeiro: Organização 
Pan-Americana da Saúde; Ministério da Saúde; Agência Nacional de Vigilância Sanitária; 2009.

4. Ferraz EM. A cirurgia segura. Uma exigência do Século XXI. Rev Col Bras Cir. 2009;36(4):281-2

5. Brennan TA, Leape LL, Laird NM, Hebert L, Localio AR, Lawthers AG, et al. Incidence of adverse events and negligence in hospitalized patients. Results of the Harvard Medical Practice Study. N Engl J Med. 1991;324(6):370-6.

6. Schlack WS, Boermeester MA. Patient safety during anaesthesia: incorporation of the WHO safe surgery guidelines into clinical practice. Curr Opin Anaesthesiol. 2010;23(6):754-8.

7. Norton EK, Rangel SJ. Implementing a pediatric surgical safety checklist in the OR and beyond. AORN J. 2010;92(1):61-71.

8. Windsor JA, Petrov MS. Patient safety in medicine: are surgeons ready for checklists? ANZ J Surg. 2010;80(1-2):3-5.

9. Eagle KA, Froehlich JB. Reducing cardiovascular risk in patients undergoing noncardiac surgery. N Engl J Med. 1996;335(23):1761-3.

10. Stackhouse RA, Infosino A. Airway management. In: Miller RD, editor. Basics of anesthesia. 6th ed. Philadelphia: Elsevier; 2005. p. 223.

11. Morgan GE. Anestesiologia clínica. $4^{\mathrm{a}}$ ed. Rio de Janeiro: Revinter, 2010.

12. Cangiani LM, Posso IP, Potério GMB, Nogueira CS. Tratado de anestesiologia: manuseio da via aérea difícil. $6^{\text {a }}$ ed. Rio de Janeiro: Atheneu, 2006.

13. Gottlieb EA, Andropoulos DB. Pediatrics. In: Miller RD, editor. Basics of anesthesia. 6th ed. Philadelphia: Elsevier; 2005. p. 1062.

14. Runciman WB. Lessons from the Australian Patient Safety Foundation: setting up a national patient safety surveillance system - is this the right model? Qual Saf Health Care. 2002;11(3):246-51.

15. Nilsson L, Lindberget O, Gupta A, Vegfors M. Implementing a pre-operative checklist to increase patient safety: a 1-year follow-up of personnel attitudes. Acta Anaesthesiol Scand. 2010;54(2):176-82.
16. Mallampati SR, Gatt SP, Gugino LD, Desai SP, Waraksa B, Freiberger D, et al. A clinical sign to predict difficult tracheal intubation: a prospective study. Can Anaesth Soc J. 1985;32(4):429-34

17. Adamus M, Fritscherova S, Hrabalek L, Gabrhelik T, Zapletalova J, Janout V. Mallampati test as a predictor of laryngoscopic view. Biomed Pap Med Fac Univ Palacky Olomouc Czech Repub. 2010;154(4):339-43.

18. American Society of Anesthesiologists Task Force on Management of the Difficult Airway. Practice Guidelines for Management of the Difficult Airway: an updated report by the American Society of Anesthesiologists Task Force on Management of the Difficult Airway. Anesthesiology. 2003;98(5):1269 77.

19. Leigh-Smith S, Harris T. Tension pneumothorax - time for a re-think? Emerg Med J. 2005;22(1):8-16.

20. Hurtado JJ, Jiménez X, Peñalonzo MA, Villatoro C, de Izquierdo S, Cifuentes M. Acceptance of the WHO Surgical Safety Checklist among surgical personnel in hospitals in Guatemala city. BMC Health Serv Res. 2012;12:169.

21. Cassinello F, Ariño JJ, Bartolomé Ruibal A, de la Pinta JC, de la Quintana FB, Espinosa ME, Ariño JJ, Bartolomé Ruibal A, de la Pinta JC, de la Quintana FB, Espinosa ME, et al. [Spanish Society of Anaesthesia (SEDAR) guidelines for pre-anaesthesia checking procedures]. Rev Esp Anestesiol Reanim. 2012;59(4):210-6

22. Runciman WB, Williamson JA, Deakin A, Benveniste KA, Bannon K, Hibbert PD. An integrated framework for safety, quality and risk management: an information and incident management system based on a universal patient safety classification. Qual Saf Health Care. 2006;15(Suppl 1):i82-90.

23. World Alliance For Patient Safety Drafting Group, Sherman H, Castro G, Fletcher M; World Alliance for Patient Safety, Hatlie M, et al. Towards an International Classification for Patient Safety: the conceptual framework Int J Qual Health Care. 2009;21(1):2-8. 